\title{
EDITORIAL
}

\section{The South African Academy of Family Physicians: new directions}

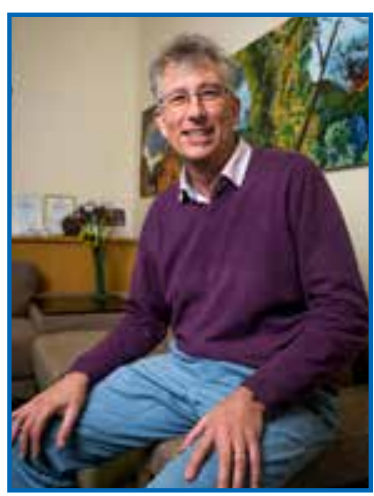

The South African Family Practice Journal is the official journal of the South African Academy of Family Physicians ${ }^{1}$ and, as the new President, I would like to bring the readership up to date with our strategic goals for the next three years and to remind you of the overall purpose of the Academy (See Box).

Mission statement of the SA Academy of Family Physicians:

- To advocate for and contribute to the strengthening of primary health care and district health services

- To develop and promote the science and art of family medicine through education, training, research and the dissemination of knowledge

- To represent and further the interests of family physicians in South Africa, Africa and other international forums

- To influence the relationship between family physicians and health facilities, public and private institutions, government authorities, healthcare funders, the public and the medical profession in general.

Currently there are 1064 family physicians on the Health Professions Council of South Africa's (HPCSA) specialist register, although not all are members of the Academy. Increasing our membership is therefore one of the key goals as we want to fully represent the discipline of family medicine in the country. You do not have to be a family physician, however, to be a member of the academy and we welcome all medical practitioners working in the field of family medicine. All those that receive a hardcopy of the journal should be members of the Academy.

One of the other areas that we want to focus on in the next few years is advocating for the discipline and our contribution to the strengthening of primary health care and district health services. ${ }^{2}$ We would like to be recognised as leaders of clinical governance and quality in the district health system.

The council recently developed a detailed plan for engaging with our key stakeholders: department of health, private sector medical aids and funders, university departments, professional bodies and the general public. We represent the discipline globally through WONCA (World Organization of Family Doctors), who will be celebrating World Family Doctors Day on 19 May. ${ }^{3}$ We are also a formal specialist society within the South African Medical Association (SAMA) and are represented on their various committees.
The Academy also includes the National Education and Training committee for family medicine. This committee includes all of the university training programmes in the country and is an opportunity for setting national standards, sharing best practice and ensuring coordination between programmes. Currently our focus is on improving the pass rate in the national exit examination. Over the last few years we have improved the quality of the examination as well as introducing a national five-day course to train clinical trainers. In the private sector we have been working hard to ensure that family physicians are recognised in terms of remuneration as well as their scope of practice. We hope to have good news to share in the near future.

The Academy is also recognised as an official accreditor of continuing professional development (CPD) by the HPCSA. In addition, we offer free CPD to our members via the Journal as well as extensive opportunities within eCPD. ${ }^{4}$ We hope to improve the CPD offerings even more over the next few years. The National Family Practitioners Conference is another annual opportunity for CPD and engaging with your colleagues in the discipline of family medicine. This year the 21st conference will be held in Cape Town from 24-26 August and we hope to see more of you there. ${ }^{5}$ The theme this year is "Family Medicine and the Circle of Life". There will be an emphasis on the "first thousand days" and the contribution of family doctors throughout the continuum of life, including palliative care. The Journal itself is an important contribution to CPD, dialogue within the discipline and dissemination of relevant research. We need to work hard to improve the visibility and impact factor of the Journal.

In addition, the Academy hopes to strengthen its engagement with our partner organisations such as the Rural Doctors Association of South Africa, WONCA and SAMA. We also hope to build stronger bridges with other medical generalists, be they general practitioners, nurse practitioners or clinical associates.

\section{Prof Bob Mash}

President: SA Academy of Family Physicians

\section{References}

1. SAAFP. South African Academy of Family Physicians. 2018. http://saafp.org/ (accessed April 5, 2018).

2. Mash $\mathrm{R}$, Pressentin $\mathrm{K}$ Von. Family medicine in South Africa: exploring future scenarios. South African Fam Pract J. 2017; 59. DOI:10.1080/20786190.2016.1272 231.

3. WONCA. World Family Doctor Day. 2018. http://www.globalfamilydoctor.com/ member/ForMemberOrganizations/WorldFamilyDoctorDay (accessed April 5, 2018).

4. eCPD $^{\circledR}$ COURSES - AOSIS. https://www.aosis.co.za/ecpd-courses (accessed April 19, 2018).

5. 21st National Family Practitioners Congress 2018. http://saafp.org/conferences/ index.php/ANFPC/2018 (accessed April 19, 2018). 